\title{
Breastfeeding and introduction of solid foods in Swedish infants: the All Babies in Southeast Sweden study
}

\author{
Hilde K. Brekke ${ }^{1}$, Jonas F. Ludvigsson ${ }^{2,3}$, Jenny van Odijk ${ }^{1}$ and Johnny Ludvigsson ${ }^{4}$ \\ ${ }^{1}$ Department of Clinical Nutrition, Sahlgrenska Academy at Göteborg University, Box 459, 40530 Göteborg, Sweden \\ ${ }^{2}$ Paediatric Department, Örebro University Hospital, Örebro, Sweden \\ ${ }^{3}$ Clinical Epidemiology Unit, Department of Medicine, Karolinska University Hospital, Karolinska Sweden \\ ${ }^{4}$ Division of Paediatrics and Diabetes Research Centre, Department of Molecular and Clinical Medicine, Faculty of Health Sciences, \\ Linköping University, Linköping, Sweden
}

(Received 17 December 2004 - Revised 21 March 2005 - Accepted 5 April 2005)

\begin{abstract}
The aim of this report is to describe breastfeeding duration and introduction of foods in Swedish infants born 1997-9, in relation to current recommendations. A secondary aim is to examine breastfeeding duration and introduction of certain allergenic foods in allergy-risk families (for whom allergy-preventive advice has been issued). Out of 21700 invited infants, screening questionnaires were completed for 16070 infants after delivery. Parents to 11081 infants completed a follow-up questionnaire regarding breastfeeding and introduction of foods and 9849 handed in detailed food diaries at 1 year of age. The percentages of infants who were exclusively breast-fed at 3,6 and $\geq 9$ months of age were $78 \cdot 4,10 \cdot 1$ and 3.9, respectively. The corresponding percentages for partial breastfeeding were 87.8, 68.9 and 43.6 . Gluten-containing foods were introduced to $66 \%$ of infants between 4 and 6 months, as recommended at the time of the study, and one-quarter had stopped breastfeeding when gluten was introduced. More than $90 \%$ of parents introduced the first sample of solid food during months 4-6, as recommended. Fish and eggs had been introduced during the first year in $43 \%$ and $29 \%$, respectively, of infants with atopic heredity. Exclusive breastfeeding duration and time of introduction of solid foods, including gluten, seemed to have been in line with Swedish recommendations at the time, although gluten was often introduced late, and not during ongoing breastfeeding as recommended. The adherence to allergy-preventive advice was less than optimal in infants with atopic heredity.
\end{abstract}

Breastfeeding: Introduction: Solid foods: Allergy risk: Recommendations

Exclusive breastfeeding is being promoted because of its health effects. However, the optimal duration of exclusive breastfeeding has been debated (Kramer \& Kakuma, 2002). The WHO now recommends that infants should be breast-fed for at least 2 years with weaning foods added at 6 months (World Health Organization, 1998). The American Academy of Pediatrics also recommends exclusive breastfeeding as the ideal nutrition in infants for approximately the first 6 months after birth (American Academy of Pediatrics Work Group on Breastfeeding, 1997).

The rates of breastfeeding are very high in Sweden compared with those in the rest of the world (World Health Organization, 2003). Data from Official Statistics of Sweden show that increasing breastfeeding rates were observed during the 1990s, coinciding with UNICEF's Baby Friendly Hospitals Initiative (The National Board of Health and Welfare, 2001). Recommendations in Sweden, regarding breastfeeding and introduction of solid foods, are issued by The National Board of Health and Welfare, and by the committee on Nutrition and Health of the Swedish Paediatric Association and the National Food Administration. The main concerns/topics of debate that have resulted in revised recommendations are: (1) the timing of the introduction of gluten (Lindberg, 1996); (2) the timing of the introduction of cow's milk (Axelsson et al. 1999b); (3) the use of vitamin A supplementation (Axelsson et al. 1999a).
In addition, the Swedish Association of Paediatric Allergologists issues allergy-preventive advice (Swedish Association of Paediatric Allergologists, 2003). Exclusive breastfeeding, use of extensively hydrolysed infant formulas and avoidance of fish, eggs and other allergenic foods seem to reduce the risk of allergy, and therefore form an important part of allergy prevention (Arshad et al. 1992; Oldaeus et al. 1997; Kull et al. 2002; van Odijk et al. 2003). Longer breastfeeding duration may also protect against type 1 diabetes (Virtanen et al. 1991, 1992; SadauskaiteKuehne et al. 2004) while early introduction of cow's milk proteins seems to increase the risk for type 1 diabetes (Virtanen et al. 1991).

During 1997-9, when the present study was conducted, Swedish recommendations regarding breastfeeding and introduction of solid foods were that only breast-milk was to be given during the first 4-6 months. Between 4 and 6 months of age, samples of solid foods and gluten should then be introduced. In high-risk groups for allergies (two or more first-degree relatives with atopic disease), eggs and fish should be avoided during the first 12 months. If supplemental feeding was needed before 4 months of age in these high-risk groups for allergies, extensively hydrolysed formula was recommended.

Although reliable statistics regarding breastfeeding are published annually in Sweden, less is known about the prevalence 
of exclusive breastfeeding (as defined by World Health Organization, 1991), use of formulas and introduction of solid foods in the population. Such information is of interest in relation to the development of both allergy and type 1 diabetes, and it is important to know how recommendations to prevent a disease like allergy is followed, especially in families with a high risk of developing atopic disease.

The aim of the present study is to describe breastfeeding duration and introduction of foods, in relation to current recommendations, in a large sample of Swedish infants. A secondary aim is to examine breastfeeding duration and introduction of certain allergenic foods in allergy-risk families for whom allergypreventive advice has been issued.

\section{Material and methods}

This report is based on the 1-year follow-up of infants who are part of the All Babies in Southeast Sweden (ABIS) study. Parents to 21700 infants were invited to participate in this prospective cohort study from 1 October 1997 to 1 October 1999. Mothers to 16070 infants completed a screening questionnaire after delivery. That questionnaire was completed just before leaving the maternity ward or at home (and in the latter case returned to the responsible nurse/doctor at the time of regular infant checkup). Follow-up questionnaires at 1 year of age were available from 11081 participants, and detailed food diaries from 9849.

Baseline data about the parents and associated factors were collected from the screening questionnaires at birth. The 1-year follow-up questionnaire contained questions about duration of exclusive breastfeeding, any breastfeeding and time for introduction of formulas and other semi-solid (infant formula, follow-on formula, cow's milk) and solid foods (porridge, first solid food, commercially produced foods), including use of vitamin and mineral supplements. Answers in the 1-year questionnaire were given in categories of months, usually from 1 to $\geq 9$. As an example, the question regarding introduction of gluten reads: When did the child receive gluten (e.g. in cereals, pasta, macaroni, bread, etc.) for the first time?

The detailed food diary included information about the exact duration of breastfeeding and time (date) for introduction of different food items during the first year. Due to the lower number of completed food diaries, data from the detailed food diary were only used to examine the timing for introduction of fish and eggs. All other results were based on data from the 1year follow-up questionnaire.

\section{Definitions of breastfeeding terms and atopic heredity}

Throughout the paper the following definitions have been used. Exclusive breastfeeding is defined as the infant receiving only breast-milk. Since we did not ask for intake of syrups, medicines and smaller amounts of liquid, the present study deviates from the strict definition of exclusive breastfeeding suggested by Labbok \& Krasovec (1990). Partial breastfeeding is defined as breastfeeding in addition to formula or other food. We defined atopic heredity as having at least two first-degree relatives (mother, father or sibling) who had asthma, cow's milk protein allergy or allergy to another kind of food.

\section{Analyses and statistics}

Pearson $\chi^{2}$ test (with Yates' correction) or the Fisher's exact test (in $2 \times 2$ tables where the expected value of one of the four cells was $<5$ ) was used to compare proportions of infants who had received foods before 1 year of age.

SPSS for Windows version 11.5.1 (SPSS, Chicago, IL, USA) was used for all statistical analyses.

\section{Ethics}

The present study was part of the ABIS study, which has been approved by the Research Ethics Committees of the Faculty of Health Sciences, Linköping University and the Medical Faculty of Lund University. Mothers gave their consent after careful written as well as verbal information and information via videotape.

\section{Results}

Characteristics of the parents and the infants are presented in Table 1 and based on 11081 participating infants. The average age of the participating infants at the time of the follow-up was $12 \cdot 1$ months.

\section{Breastfeeding data}

The percentages of infants that were exclusively breast-fed at 3,6 and $\geq 9$ months were $78 \cdot 4,10 \cdot 1$ and $3 \cdot 9$, respectively (Fig. 1). The percentages that were partially breast-fed at 3 and 6 months were 87.8 and 68.9 , respectively, while $43.6 \%$ were partially breast-fed to at least 9 months of age.

Table 1. Characteristics of the parents at the time of delivery and the characteristic of the child at birth and at the 1-year follow-up*

(Mean values and standard deviations)

\begin{tabular}{|c|c|c|}
\hline Characteristic & Mean & SD \\
\hline \multicolumn{3}{|l|}{ Parents } \\
\hline Maternal age at delivery (years) & $29 \cdot 8$ & 4.5 \\
\hline Paternal age at delivery (years) & $32 \cdot 2$ & $5 \cdot 4$ \\
\hline $\begin{array}{l}\text { Education level of mother } \\
\leq 9 \text { years } / 10-12 \text { years } / \geq 13 \text { years }(\%)\end{array}$ & $7 \cdot 3 / 59 \cdot 4 / 33 \cdot 3$ & \\
\hline $\begin{array}{l}\text { Education level of father } \\
\leq 9 \text { years } / 10-12 \text { years } / \geq 13 \text { years }(\%)\end{array}$ & $13 \cdot 2 / 62 \cdot 2 / 24 \cdot 7$ & \\
\hline Maternal smoking during pregnancy $(\%)$ & $9 \cdot 3$ & \\
\hline Caesarean delivery $(\%)$ & $11 \cdot 6$ & \\
\hline Swedish / non-Swedish mother (\%) & $94 \cdot 3 / 5 \cdot 7$ & \\
\hline Swedish/non-Swedish father (\%) & $93 \cdot 9 / 6 \cdot 1$ & \\
\hline Primiparous (\%) & $39 \cdot 2$ & \\
\hline $\begin{array}{l}\text { Mother working outside home } \\
\text { during pregnancy }(\%)\end{array}$ & $84 \cdot 0$ & \\
\hline Single mother/co-habitant/married (\%) & $1 \cdot 6 / 55 \cdot 5 / 42 \cdot 9$ & \\
\hline \multicolumn{3}{|l|}{ Infants } \\
\hline$n$ & 11081 & \\
\hline Boys/girls (\%) & $51 \cdot 9 / 48 \cdot 1$ & \\
\hline Weight at birth $(\mathrm{g}) \dagger$ & 3583 & 540 \\
\hline Gestational age (weeks)† & $39 \cdot 8$ & $1 \cdot 7$ \\
\hline Age at follow-up (months) & $12 \cdot 1$ & \\
\hline Weight at 1 year $(\mathrm{g})$ & 10170 & 3164 \\
\hline Length at 1 year $(\mathrm{cm})$ & $76 \cdot 0$ & $13 \cdot 6$ \\
\hline
\end{tabular}

*Missing data maximum $4.4 \%$.

†Infants born during weeks $22-43$ or with a birth weight in the interval $400-6000 \mathrm{~g}$ are included in the analysis.

For details of subjects and procedures, see p. 378. 


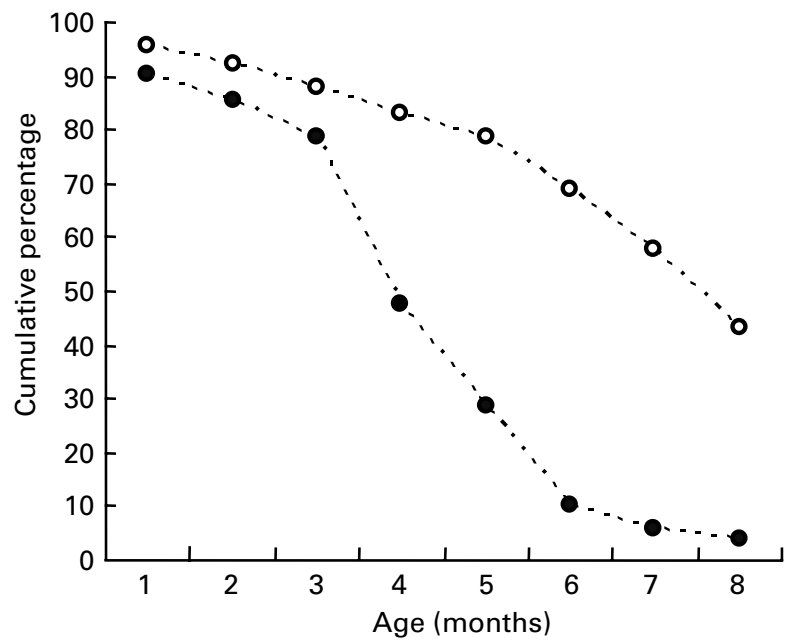

Fig. 1. Cumulative percentages for duration of exclusive (•, n 10434) and partial $(O, n$ 10541) breastfeeding. The percentages of infants who were breast-fed exclusively and partially for 9 months or longer were 3.9 and 43.6 , respectively. For details of subjects and procedures, see p. 378.

\section{Introduction of cow's milk}

Only $0.5 \%$ of infants had received cow's milk before 4 months (30.2\% before 6 months of age; Fig. 2). The age for the first introduction of yoghurt/sour milk was similar to that for cow's milk.

\section{Introduction of gluten}

Gluten-containing foods were introduced to $0.6 \%$ of infants before 4 months and to $33.9 \%$ after 6 months (Fig. 2). Breastfeeding had stopped the month before gluten was introduced, or earlier, for $24 \%$ of infants. One out of ten infants stopped breastfeeding the same month as they were introduced to gluten, and two-thirds were still breast-fed the month after gluten had been introduced, or later. Out of the infants who were weaned before or the same month as gluten was introduced, $50 \%$ had been introduced to gluten during months $4-6$ and $50 \%$ at 7 months or later.

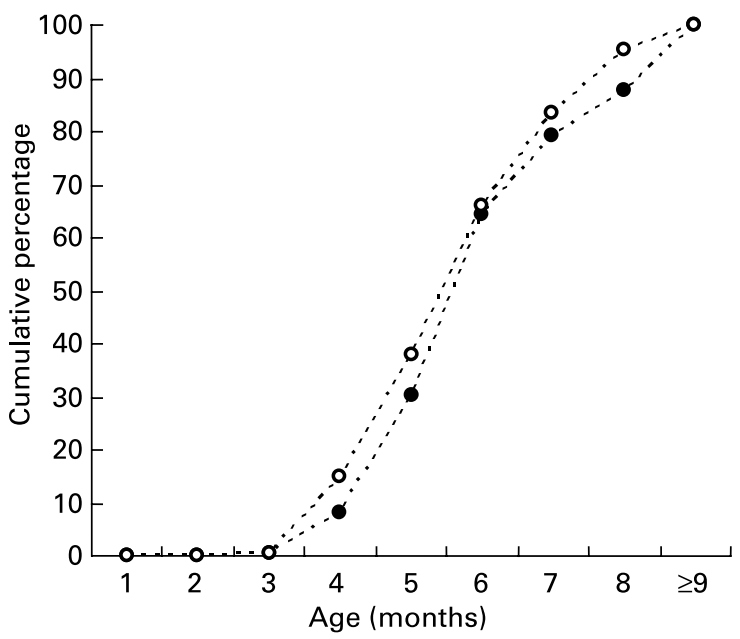

Fig. 2. Cumulative percentages for time of introduction of cow's milk $(\bullet, n$ $10550)$ and gluten $(O, n 10726)$. For details of subjects and procedures, see p. 378.
Introduction of other foods

Out of 10643 infants, $0.2 \%$ were first given solid food during month 2 , and $4.4 \%$ during month 3 (Fig. 3 ). The vast majority $(91.7 \%)$ of infants were introduced to solid food during months $4-6$, with $3.7 \%$ at 7 months or later. The most common first foods were potatoes, carrots and sweetcorn or products that consisted of these ingredients. The proportion of infants who had been given commercially produced foods was similar, only with a slight time delay in introduction (Fig. 3). The introduction of porridge and follow-on formula is shown in Fig. 4.

\section{Use of vitamin and mineral supplements}

Supplementation with drops containing vitamins A and D was given to $99 \%$ of the infants. Other vitamin or mineral supplementation was given to $2.1 \%$ of the infants, and $1.1 \%$ received $\mathrm{Fe}$ supplementation.

\section{Allergy-risk families}

Of the infants who were part of the 1-year follow-up, $3.0 \%$ had an atopic heredity. The corresponding percentage in those who had dropped out during the first-year of follow-up was 3.4 $(P=0 \cdot 250)$. A larger proportion of those with atopic heredity received cow's milk-free formula as compared with infants without atopic heredity $(23.3 \% v .15 .4 \%, P<0.001)$. Among the infants whose mother stopped breastfeeding before 4 months, cow's milk-free formula was more often given to those with than to those without heredity for allergies $(35.7 \% v .22 \cdot 0 \%, P=0.037)$.

According to the food diaries, $68.8 \%$ of the infants had been given fish and $44.6 \%$ had been given eggs before 1 year of age. Infants with atopic disease less often received fish $(42.7 \%$ v. $69.6 \%$ for the controls, $P<0.001)$ or eggs $(29.4 \%$ v. $45.1 \%$ for the controls, $P<0.001)$ during their first year of life.

\section{Discussion}

The present study, a questionnaire-based population study based on some 10000-11000 infants, indicates that breastfeeding frequency in Swedish infants during 1997-9 was in line with current

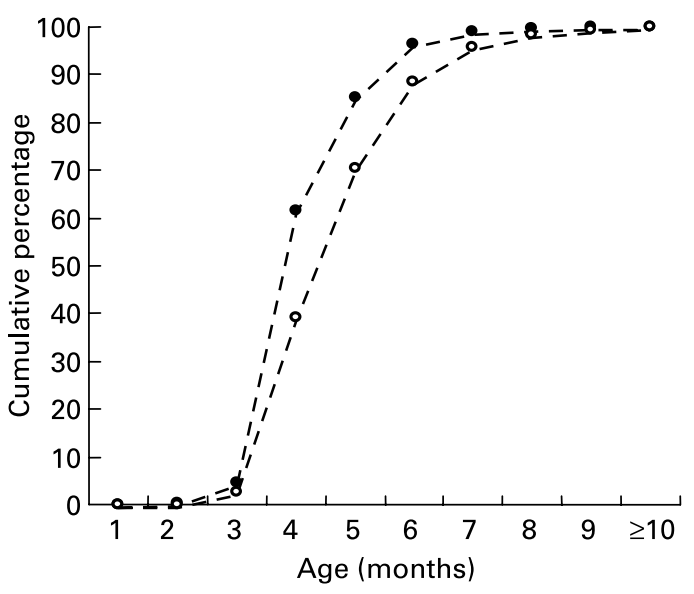

Fig. 3. Cumulative percentages for time of introduction of first solid food $(\bullet, n$ 10643) and of commercially prepared food $(0, n$ 10607). For details of subjects and procedures, see p. 378 . 


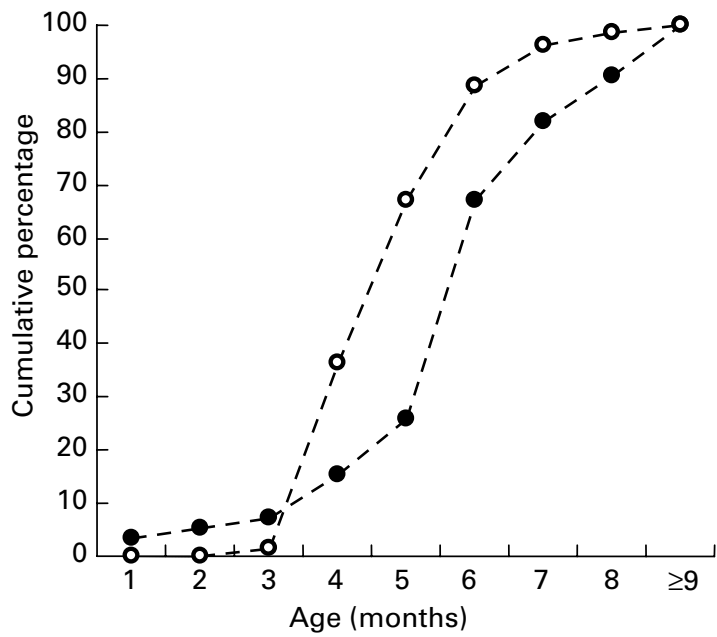

Fig. 4. Cumulative percentages for time of introduction of follow-on formula (-, n 9742) and porridge $(O, n$ 10732). For details of subjects and procedures, see p. 378

recommendations, i.e. almost $85 \%$ were breast-fed until 4 months of age. However, only $66 \%$ introduced gluten-containing foods between 4 and 6 months, as recommended at the time of the study, and one-quarter had stopped breastfeeding when gluten was introduced. Over $90 \%$ of infants were introduced to solid food during the recommended 4-6 months. Introduction of fish and egg in allergy-risk families was not in accordance with current allergy-preventive advice.

The data on total breastfeeding are in good agreement with Swedish national statistics on breastfeeding for the same area during the study period (1997-9; The National Board of Health and Welfare, 2001). Data are also consistent with the breastfeeding prevalence in the whole country during the years 1997-9, showing that about $92 \%, 84 \%$ and $73 \%$ were breast-fed at age 2, 4 and 6 months, respectively (The National Board of Health and Welfare, 2001). Our data on exclusive breastfeeding are, however not in agreement with data from Official Statistics of Sweden (The National Board of Health and Welfare, 2001) especially not in infants $>2$ months. This is probably due to differences in definitions of exclusive breastfeeding. While we used a definition based on the WHO definition (World Health Organization, 1991), exclusive breastfeeding rates from Official Statistics of Sweden include breast-fed infants who might have received taste portions of other foods. This explains the higher rates in their report (35-40\%) compared with $10 \%$ at 6 months in the present study.

Although, our definition of exclusive breastfeeding was based on the WHO definition (World Health Organization, 1991), it differs to some extent from that strict definition. Mothers were not asked to consider the use of drops or syrups consisting of vitamin or mineral supplements or medicines when reporting the duration of exclusive breastfeeding. This may well affect the exclusive breastfeeding rates. In addition, data were collected at 1 year of age and there is a risk of recall bias (Huttly et al. 1990). However, that risk should not be overestimated as Launer et al. (1992) have shown that mothers, albeit in a non-Western setting, may well be aware of the breastfeeding duration of their latest child. In addition, previous research by Samuelsson \& Ludvigsson (2001) has shown a high correlation between questionnaire data on breastfeeding and data on breastfeeding reported independently of any study at the child health-care centres in the ABIS study area.
The average exclusive breastfeeding duration in the present study was similar to that among Norwegian infants (Lande et al. 2003). In the study by Lande et al. (2003), the proportion of exclusively breast-fed infants reached $70 \%$ at 3 months but had declined to $7 \%$ at 6 months. These percentages are also consistent with data from Iceland (Atladottir \& Thorsdottir, 2000) and Denmark (Michaelsen et al. 1994), showing a relatively high prevalence of breastfeeding in Scandinavia, compared with other parts of the Western world (Freeman et al. 2000; Briefel et al. 2004; Giovannini et al. 2004). Possible explanations for the high breastfeeding rates in Sweden are good conditions for maternity leave, ongoing campaigns promoting breastfeeding and the social acceptability of breastfeeding in public places.

The American Academy of Pediatrics recommends that the introduction of cow's milk should be delayed until 1 year of age due to risk of Fe deficiency (American Academy of Pediatrics Committee on Nutrition, 1992). During 1999-2000, there were no Swedish recommendations with regard to the introduction of cow's milk. Cow's milk could, like other foods, be introduced between 4 and 6 months, and our data show that $50 \%$ of the infants were first given cow's milk between 4 and 6 months, although as many as $35 \%$ were not introduced until after the age of 6 months. Very few parents in our study introduced cow's milk before 4 months of age, and the proportions are similar to those in Italy and the USA (Briefel $e$ al. 2004; Giovannini et al. 2004). In 1999, there were new recommendations on the introduction of cow's milk and cow's milk products (not to be started until 10-12 months of age) (Axelsson et al. $1999 b$ ) even though we know that most food products given to infants already from the age of 4 months contain cow's milk protein.

The vast majority was compliant with the recommendation for introduction of solid foods, and less than $5 \%$ had introduced solids before the child was 4 months of age. The corresponding percentages from Norway, the USA, New Zealand and Europe were as high as 21, 29, 45 and 46, respectively (Freeman et al. 2000; Heath et al. 2002; Lande et al. 2003; Briefel et al. 2004). In Glasgow, only $7 \%$ of infants had not been weaned before the age of 4 months (Savage et al. 1998) and in Italy introduction of solids before the age of 3 months was seen in $5.6 \%$, indicating that solid foods are introduced early compared with infants in the present study (Giovannini et al. 2004). The recommendation regarding timing of introduction of solids seems to have been very well implemented in this Swedish population.

Data from various countries show that the types of supplementary food first given to infants differ between countries (Savage et al. 1998; Freeman et al. 2000; Norris et al. 2002; Giovannini et al. 2004). In the UK, more than $80 \%$ of preterm infants received baby rice as their initial non-breastmilk food (Norris et al. 2002), and in Glasgow $82 \%$ of infants were given commercially prepared cereals (Savage et al. 1998). In the Euro-Growth study, fruits $(73 \%)$ and cereals $(51 \%)$ were the first foods given to most infants (Freeman et al. 2000). The same foods were also introduced first in Italy (Giovannini et al. 2004), while in the present study population, potatoes, carrots and sweetcorn were seen as the ideal first food.

The timing of introduction of gluten has been under debate during the past two decades in Sweden, due to an increased incidence of coeliac disease in the 1980s (Ivarsson et al. 2000). This increase was thought to be due to the increased use of glutencontaining foods, introduced around 6 months of age, i.e. around the time when many women stop breastfeeding. The increase in coeliac disease resulted in a new recommendation in 
1996 to introduce gluten during months $4-6$ when the infant is likely to still be breast-fed. The new recommendation came into effect 1 year before the data in the present study were collected. Although the majority of the present study participants had introduced gluten during 4-6 months of age, $34 \%$ introduced gluten later than 6 months of age. These numbers are similar to those observed in a Swedish study performed 2 years later, showing that as many as $45 \%$ had avoided gluten until 6 months of age (van Odijk et al. 2004).

Our data showed that $24 \%$ of the mothers did not breastfeed at the time of gluten introduction, and an additional $10 \%$ breast-fed at the time of gluten introduction but not beyond the month of introduction. It may hence be that one-third of the infants did not benefit from the protective effect of breastfeeding with regard to coeliac disease (Ivarsson et al. 2002). Some $50 \%$ of these infants were first fed gluten during months $4-6$, and the others at 7 months or later. This indicates that half of those who were compliant with the recommended timing of gluten introduction were actually non-compliant with the actual recommendation of concurrent introduction with breastfeeding. We cannot say if this non-compliance is due to lack of knowledge or other reasons, but it seems likely that clear information about the actual aim of this recommendation could improve adherence to the recommendations.

Only $1 \%$ of the ABIS study children did not receive the recommended vitamins A and D supplementation (Axelsson et al. 1999a). This is important as lack of vitamin D has been proposed to increase the risk of type 1 diabetes (Hypponen et al. 2001). Supplementation with vitamin D is also recommended in Norway, however, compliance there was only $80 \%$ (Lande et al. 2003). There is no uniform recommendation regarding vitamin supplementation in Europe, and the highest rate of vitamin supplementation observed in the Euro-Growth study was $71.5 \%$ at 5 months (Freeman et al. 2000).

About $3 \%$ of the infants in the present study had an atopic heredity, which is slightly less than previous estimations by Croner \& Kjellman (1990). These families should receive information about the prophylactic effect of extensively hydrolysed formulas if breastfeeding is not possible. It is, however, not known to what extent this information or allergy-preventive advice is actually given. Our results indicate that there is a significant difference in practice between allergy-risk families and those with no or one parent or sibling with atopic disease. Still some $30-40 \%$ of the infants in families with atopic heredity had been given fish and eggs during the first year. This is less than previously reported from Sweden (van Odijk et al. 2004). However, it appears as if compliance to allergy-preventive advice is low, or alternatively that the advice does not reach the families. At present, due to lack of data on the longterm effect of avoidance of food allergens, much of the primary prevention advice has been withdrawn.

In conclusion, exclusive breastfeeding duration and the introduction of solid foods, including gluten, seemed to have been in line with Swedish recommendations at the time, although gluten was often introduced late, and not during ongoing breastfeeding as recommended. Meanwhile, the compliance to allergy-preventive advice was less than optimal in infants with atopic heredity. Early nutrition may influence the development of immune-mediated diseases, hence the message on dietary recommendations has to be clear and based on solid knowledge to reach common adherence in the population.

\section{Acknowledgements}

We are very grateful to all children and their parents participating in the study (ABIS), as well as to the health centres where all questionnaires were collected and biological samples taken. We are grateful to Lena Berglert, Gosia Smolinska and Cecilia Rundquist, who have been of great help in the autoantibody determinations. This study, as a part of the ABIS project, was generously supported by JDRF-Wallenberg foundations (K 98-99D12813-01A), The Swedish Medical Research Council (MFR; Vetenskapsrådet, K99-72X-11242-05A), The Swedish Child Diabetes Foundation (Barndiabetesfonden), The Swedish Diabetes Association, Swedish Diary Association R \& D, the Majblomman Foundation and the Novo Nordisk Foundation.

\section{References}

American Academy of Pediatrics Committee on Nutrition (1992) The use of whole cow's milk in infancy. Pediatrics 89, 1105-1109.

American Academy of Pediatrics Work Group on Breastfeeding (1997) Breastfeeding and the use of human milk. Pediatrics 100, 1035-1039. Arshad SH, Matthews S, Gant C \& Hide DW (1992) Effect of allergen avoidance on development of allergic disorders in infancy. Lancet 339, 1493-1497.

Atladottir H \& Thorsdottir I (2000) Energy intake and growth of infants in Iceland - a population with high frequency of breast-feeding and high birth weight. Eur J Clin Nutr 54, 695-701.

Axelsson I, Gebre-Medhin M, Hernell O, Jakobsson I, Michaelsen KF \& Samuelson G (1999a) The AD-drops can be replaced by D-drops. Lakartidningen 96, 2200-2204.

Axelsson I, Gebre-Medhin M, Hernell O, Jakobsonn I, Michaelsen KF \& Samuelson G (1999b) Recommendations for prevention of iron deficiency. Delay cow's milk intake as a beverage to infants until 10-12 months of age!. Lakartidningen 96, 2206-2208.

Briefel RR, Reidy K, Karwe V \& Devaney B (2004) Feeding infants and toddlers study: improvements needed in meeting infant feeding recommendations. J Am Diet Assoc 104, S31-S37.

Croner S \& Kjellman N-IM (1990) Development of atopic disease in relation to family history and cord blood IgE levels. Eleven-year follow-up in 1654 children. Pediatr Allergy Immunol 1, 14-20.

Freeman V, van't Hof M \& Haschke F (2000) Patterns of milk and food intake in infants from birth to age 36 months: the Euro-Growth study. J Pediatr Gastroenterol Nutr 31, Suppl. 1, S76-S85.

Giovannini M, Riva E, Banderali G, Scaglioni S, Veehof SH, Sala M, Radaelli G \& Agostoni C (2004) Feeding practices of infants through the first year of life in Italy. Acta Paediatr 93, 492-497.

Heath AL, Tuttle CR, Simons MS, Cleghorn CL \& Parnell WR (2002) A longitudinal study of breastfeeding and weaning practices during the first year of life in Dunedin. New Zealand. J Am Diet Assoc 102, 937-943.

Huttly SR, Barros FC, Victora CG, Beria JU \& Vaughan JP (1990) Do mothers overestimate breast feeding duration? An example of recall bias from a study in southern Brazil. Am J Epidemiol 132, 572-575.

Hypponen E, Laara E, Reunanen A, Jarvelin MR \& Virtanen SM (2001) Intake of vitamin D and risk of type 1 diabetes: a birth-cohort study. Lancet 358, 1500-1503.

Ivarsson A, Hernell O, Stenlund H \& Persson LA (2002) Breast-feeding protects against celiac disease. Am J Clin Nutr 75, 914-921.

Ivarsson A, Persson LA, Nystrom L, et al. (2000) Epidemic of coeliac disease in Swedish children. Acta Paediatr 89, 165-171.

Kramer MS \& Kakuma R (2002) The Optimal Duration of Exclusive Breastfeeding. A Systematic Review. Geneva: World Health Organization.

Kull I, Wickman M, Lilja G, Nordvall SL \& Pershagen G (2002) Breast feeding and allergic diseases in infants - a prospective birth cohort study. Arch Dis Child 87, 478-481.

Labbok M \& Krasovec K (1990) Toward consistency in breastfeeding definitions. Stud Fam Plann 21, 226-230. 
Lande B, Andersen LF, Baerug A, Trygg KU, Lund-Larsen K, Veierod MB \& Bjorneboe GE (2003) Infant feeding practices and associated factors in the first six months of life: the Norwegian infant nutrition survey. Acta Paediatr 92, 152-161.

Launer LJ, Forman MR, Hundt GL, Sarov B, Chang D, Berendes HW \& Naggan L (1992) Maternal recall of infant feeding events is accurate. J Epidemiol Community Health 46, 203-206.

Lindberg T (1996) Gluten. Changed recommendations for infant care. Society of Paediatricians, Sweden. Lakartidningen 93, 4396-4397.

Michaelsen KF, Larsen PS, Thomsen BL \& Samuelson G (1994) The Copenhagen cohort study on infant nutrition and growth: duration of breast feeding and influencing factors. Acta Paediatr 83, 565-571.

Norris FJ, Larkin MS, Williams CM, Hampton SM \& Morgan JB (2002) Factors affecting the introduction of complementary foods in the preterm infant. Eur J Clin Nutr 56, 448-454.

Oldaeus G, Anjou K, Bjorksten B, Moran JR \& Kjellman NI (1997) Extensively and partially hydrolysed infant formulas for allergy prophylaxis. Arch Dis Child 77, 4-10.

Sadauskaite-Kuehne V, Ludvigsson J, Padaiga Z, Jasinskiene E \& Samuelsson U (2004) Longer breastfeeding is an independent protective factor against development of type 1 diabetes mellitus in childhood. Diabetes Metab Res Rev 20, 150-157.

Samuelsson U \& Ludvigsson J (2001) Seasonal variation of birth month and breastfeeding in children with diabetes mellitus. J Pediatr Endocrinol Metab 14, 43-46.

Savage SA, Reilly JJ, Edwards CA \& Durnin JV (1998) Weaning practice in the Glasgow Longitudinal Infant Growth Study. Arch Dis Child 79, 153-156.

Swedish Association of Paediatric Allergologists (2003) http://www. barnallergisektionen.se/stenciler/17.html
The National Board of Health and Welfare, Centre for Epidemiology (2001) Statistics - Health and Diseases: Breast-feeding, Children Born 1999. Stockholm: Official Statistics of Sweden.

van Odijk J, Hulthen L, Ahlstedt S \& Borres MP (2004) Introduction of food during the infant's first year: a study with emphasis on introduction of gluten and of egg, fish and peanut in allergy-risk families. Acta Paediatr 93, 464-470.

van Odijk J, Kull I, Borres MP, et al. (2003) Breastfeeding and allergic disease: a multidisciplinary review of the literature (1966-2001) on the mode of early feeding in infancy and its impact on later atopic manifestations. Allergy 58, 833-843.

Virtanen SM, Rasanen L, Aro A, Lindstrom J, Sippola H, Lounamaa R, Toivanen L, Tuomilehto J \& Akerblom HK (1991) Infant feeding in Finnish children less than $7 \mathrm{yr}$ of age with newly diagnosed IDDM. Childhood Diabetes in Finland Study Group. Diabetes Care 14, 415-417.

Virtanen SM, Rasanen L, Aro A, Ylonen K, Lounamaa R, Tuomilehto J \& Akerblom HK (1992) Feeding in infancy and the risk of type 1 diabetes mellitus in Finnish children. The 'Childhood Diabetes in Finland' Study Group. Diabet Med 9, 815-819.

World Health Organization (1991) Indicators for assessing breastfeeding practices. Report of an informal meeting in June 1991. http://www. who.int/child-adolescent-health/New_Publications/NUTRITION/ who_cdd_ser_91.14.pdf

World Health Organization (1998) Breastfeeding around the world: breastfeeding recommendations. http://www.breastfeedingbasics.org/cgi-bin/ deliver.cgi/content/International/recommendations.html

World Health Organization (2003) Global data bank on breastfeeding. http://www.who.int/nut/db_bfd.htm 